\title{
Effort dynamics and alternative management policies for the small pelagic fisheries of northwest Peninsular Malaysia
}

\begin{abstract}
The dynamics of fish stocks are an important consideration in determining appropriate fishery management policy. Equally crucial are the dynamics of fishing effort. Both these dynamics have been incorporated in a simulation model to analyze the bio-socioeconomic impacts of four alternative limited entry management policies for the multispecies, multigear small pelagic fishery of northwest Peninsular Malaysia. Fishing effort dynamics are determined by the difference in profits and opportunity costs. Several management alternatives are evaluated at equilibrium. Performance variables such as equilibrium catch, social profits, consumer surplus, social benefits, direct fishery employment and income of individual crew are used in the evaluation. The implications for policy makers are discussed.
\end{abstract}

Keyword: Fishing effort dynamics; License fee; Limited entry licensing; Opportunity cost of effort; Simulations 